\title{
A DIFFERENT VIEW OF LEARNING AND KNOWLEDGE CREATION IN COLLABORATIVE NETWORKS
}

\author{
Frans M. van Eijnatten \\ Dept. of Technology Management, Eindhoven University of Technology, The Netherlands \\ F.M.v.Einatten@tm.tue.nl \\ Goran D. Putnik \\ University of Minho, School of Engineering, Guimarães, Portugal ${ }^{i}$ \\ putnikgd@idps.uminho.pt
}

\begin{abstract}
This conceptual paper considers in some detail Nonaka's Dynamic Theory of Knowledge Creation. Especially the concept of Ba or Basho is explored to figure out its applicability as an alternative view of learning in Collaborative Networked Organisations (CNOS). To that end its grounding in East-Asian thinking is further analysed, and some similarities and differences with Chaordic Systems Thinking (CST) - are described. It is concluded that Nonaka's theory can support learning in $C N O$ s, and that it might be regarded an early, alternative view of CST.
\end{abstract}

\section{INTRODUCTION}

Chaordic Systems Thinking (CST) is a qualitative approach to both organisation and management, which is grounded in the Chaos and Complexity (C\&C) lens (Van Eijnatten, 2003). CST is all but new in the absolute sense of the word. It rather 'integrates' existing concepts, methods, and approaches from several authors to provide a consistent C\&C framework for learning (Van Eijnatten \& Putnik, eds., 2004), that may be used as a toolkit for both the design and explanation of the functioning of Collaborative Networked Organisations (CNOs).

Collaborative Networks (CNs) as complex, dynamical networks of Virtual Enterprises (VEs) might provide new challenges for flexibility, quality and speed in $21 \mathrm{st}-$ century business ecosystems (Miles \& Snow, 1984/ 86; Camarinha-Matos, 2004; Putnik et al., 2005). Theoretically, CNs might gain from a C\&C approach. In an earlier paper CST for CNOs was introduced, and some basic C\&C concepts were presented: Discontinuous, fractal growth; and the emergence of real novelty (Van Eijnatten, 2005). In that paper we have proposed a chaordic view of CNOs, in which the basic reconfiguration process of a dynamic virtual organisation or CNO network is seen as routine, continuous change, and in which creative processes taking place within the virtual organisations' Market of Resources (MR) - or 'breeding environment' as MR- like environment (Cunha \& Putnik, 2005) - are seen as incidences of nonroutine, discontinuous, leap-like changes (Van Eijnatten, 2005). It was suggested that in an effective organisational approach to CNOs both routine and nonroutine developments might be smoothly balanced with one another in order to keep flexibil- 
ity, creativity, and competitiveness at acceptable high levels, not only occasionally but constantly.

In this paper a well-developed Japanese approach is presented - Nonaka's (1994) 'Dynamic Theory of Organisational Knowledge Creation', and its revision by Nonaka \& Toyama (2003) - with the explicit goal to research its applicability as an alternative view of learning in CNOs. Taking into account the specific oriental context, similarities and differences between Nonaka's theory and CST are distinguished.

\section{THE CONCEPT OF BA OR BASHO}

Nonaka's 'Dynamic Theory of Knowledge Creation' is solidly based in Japanese Thinking. According to Robert Chia (1998: p. 2) Eastern thought stresses the inherent inadequacies of language and rational analysis for describing natural and social phenomena. Instead, direct knowing is highly recommended, see Box 1.

\section{Box 1 - Some basic characteristics of East-Asian thinking}

Sources: Nonaka \&Takeuchi (1995), pp. 27-32; Chia (2002), pp. 4-24; Yuasa (1987), p. 68

The following nine aspects are some fundamental characteristics of Oriental Thinking:

1. Holistic approach (unity of humanity and nature; no separation of self and nature; perception is orientation towards objects that are subtle, but, at the same time visible and concrete).

2. Non-separability of body and mind (Non-Dualism; no Cartesian Split; entire personality).

3. Co-emergence of self and other (collective and organic view of human relationships; you and I are two sides of the same coin; individual self is a secondary phenomenon, not a primary unity of reality; goal in life is existing among others harmoniously as a collective self).

4. Primacy of pure experience (knowledge, feeling and volition remain undifferentiated; direct unmediated understanding through the ongoing perfecting of action; immediacy of lived experience).

5. Primacy of acting instead of cognising (acting intuition; emphasing performative action as bodily experience).

6. Correlative instead of linear-causal thinking (iterative movement, change, and transformation instead of stasis, form and permanence; urging the harmonising of internal wills through concrete-existential engagement rather than external causal relations).

7. Language and written documentation are secondary (knowing is achieved directly through the immediate engagement of tasks rather than through the acquisition of linguistic signs and symbols; perform instead of explain; words are used only as pointers; actions speak louder than words; perfect truth cannot be expressed in words).

8. Progenerative emptiness/ absolute nothingness/ concrescence (Concrete Existentialism; grasping the absolute in a primitive state of pure unself-conscious experiencing; pure experience is prior to consciousness and words; fact from pure experience).

9. Flexible view of time and space (time is seen as a continuous flow of a permanently updated 'present'; ultimate reality is confined to 'here and now'; space is free from a fixed perspective; no fixed view- or standpoint).

Ikujiro Nonaka stresses interaction as a primary condition for knowledge creation (Nonaka, 1991). He interprets knowledge creation as a dynamic, iterative, spiraling process from, what Michael Polanyi (1967) has called, 'tacit' into explicit knowledge, and back again. The core concept in Nonaka's theory is a central time and place where information is interpreted through interacting individuals in order to become knowledge, which he indicates with the Japanese term ' $\mathrm{Ba}$ '. This concept was 
originally proposed by Kitarō Nishida, Japan's foremost theoretical philosopher of the twentieth century, and co-founder of the Kyoto school, in 1911 (Nishida, 1921; Shimizu, 1995). Based on Zen learning, he developed the Buddhist notion of 'Pure Experience' or 'Absolute Nothingness' which is both active and prior to awareness (Chia, 1998, p. 14). The individual self is secondary. According to Nishida, facts can only be acquired from direct, on-the-spot, personal experience. Nishida (1970: pp. $61-41,68,80-84)$ distinguished three concentric fields or 'Bashos' in his 'logic of judgment' (as summarized by Chia, 1998: pp. 14-15). The following summing-up was further edited by the authors of this paper:

- Basho of Being: Empirical judgments are made unreflectively (i.e., the observing self is ignored).

- Basho of Relative Nothingness: Existential judgments (self-consciousness of the self; self as acting intuition).

- Basho of Absolute Nothingness (or Tao): Purified experience (direct knowing by pure experience of the complexity of the ultimate reality, in which all distinctions - like subject/ object - converge). Progenerative field of primordial knowing, prior to consciousness and words.

Nonaka adapted Nishida's notion of Basho to fit his Dynamic Theory of Knowledge Creation. Nonaka and associates define $\mathrm{Ba}$ as a "fertile ground" (Nonaka \& Nishiguchi, 2001: p. 3), as a spontaneous or man-built "context that harbors meaning" (Nonaka et al., 2001: p. 19), as a background for learning, as a "platform where knowledge is created, shared, and exploited" (Nonaka et al., 2001: p. 19). Ba is "a shared context in cognition and action" (Nonaka et al., 2000b: p. 8); "Ba is fluid, and can be born and disappear quickly" (Nonaka et al., 2000b: p. 8); "Ba has a "here and now' quality" (Nonaka et al., 2000a: p. 15). According to Nonaka \& Nishigushi (2001: p. 4): "Ba is a shared time and space for emerging relationships - either physical, virtual, or mental - shared by two or more individuals or organisations." $\mathrm{Ba}$ (Basho) is defined as a holonic concept:

"Ba exists at many levels and these levels may be connected to form a greater Ba (known as Basho). The self is embraced by the collective when an individual enters the Ba of teams. $J$ ust as the Ba for individuals is the team, the organisation in turn is the Ba for the teams. Finally, the market environment is the Ba for the organisation. Ba is of fundamen-tal importance for knowledge creation, and this creative process is amplified when these $B a$ conjoin to form a Basho."

Nonaka \& Konno (1998: p. 41)

A firm is a dynamic configuration of 'Ba' (Nonaka et al., 2000b: p. 8). Nonaka and associates distinguish between four types of Ba (Nonaka \& Konno, 1998: p. 46; Nonaka et al., 2000b: p. 10; Nonaka et al., 2001: pp. 20-21):

- Originating or Primary Ba: Subjective, ontological, existential field. Physical world, time and space of day-to-day social interaction where individuals share feelings, emotions, experiences, and mental models (tacit knowledge). Central characteristics: Physical, individual (face- to- face), context for socialisation, empathising.

- Dialoguing or Interacting Ba: Collective, reflective field. Physical world, conscious-ly constructed time and space of interaction where mental models (tacit knowledge) are shared, and analyzed. The space is man-made, for instance by careful selection of 
heterogeneous team members. Basic characteristics: Physical, collective (peer-to-peer), context for externalisation, articulating.

- Systematising or Cyber Ba: Collective, interactive field. Virtual world, cyber space where combination of new and existing explicit knowledge take place in collabora-tive networks. Essential characteristics: Virtual, collective (group-to-group), context for combination, connecting.

- Exercising Ba: Subjective, synthetic field. Physical world, consciously constructed time and space of interaction where explicit knowledge is internalized by on-the-job training and participation. Main characteristics: Physical, individual (on-the-site), explicit, context for internalisation, embodying.

Recently, Ba was reconceptualized as "a shared context in motion, which can transcend time, space, and organisational boundaries to create knowledge" (Nonaka \& Toyama, 2003: p. 2). "Ba should be understood as a multiple interacting mechanism explaining tendencies for interactions that occur at a specific time and space" (Nonaka \& Toyama, 2003: p. 6). "Thus $\mathrm{Ba}$ is a continuously created generative mechanism that explains the potentialities and tendencies that either hinder or stimulate knowledge creative activities" (Nonaka \& Toyama, 2003: p. 6). Nonaka and Konno (1998) define learning in a rather indirect way:

"To participate in a Ba means to get involved and transcend one's own limited perspective or boundary. This exploration is necessary in order to profit from the 'magic synthesis' of rationality and intuition that produces creativity. Within an organisation, then, one can both experience transcendence in $\mathrm{Ba}$ and yet remain analytically rational, achieving the best of both worlds."

Nonaka \& Konno (1998: p. 41)

This quotation illustrates how well Nonaka's approach fits a C\&C approach: Selftranscendence is a key issue. Nevertheless, its source is rather different, and is deeply rooted in Oriental thinking, see Box 1. Robert Chia (1998: p.1) remarks: "Theory is available in the rich tradition of Eastern thought where Complexity is understood as 'nothingness', absence, decentredness, and 'unspeakability' and where the language is elliptical, allusory, implicit and immanent."

\section{BA/ BASHO AS PLATFORMS FOR LEARNING AND KNOWLEDGE CREATION IN A CNO}

We propose the use of Nonaka's theory for the design and explanation of the functioning of CNOs, especially with respect to $\mathrm{Ba} /$ Basho for learning and knowledge creation. These environments are shown in Figure 1, in an ad-hoc representation of a CNO - as conceptualised by ECOLEAD (2004) - i.e., Mono-Disciplinary Professional Virtual Communities (PVCs) together with a Multi-Disciplinary Virtual Organisation Breeding Environment (VBO), and a number of Dynamic Virtual Organisations (DVOs). Such a CNO may provide "a common platform where knowledge is created, shared, and exploited" (Nonaka et al., 2001: p. 19), which is the definition of a 'Ba' or 'Basho'. People who are interacting in the CNO's Basho get involved and transcend their own limited perspectives or boundaries. For an illustration of the CNO's Basho, see the concentric circles in Figure 1. 


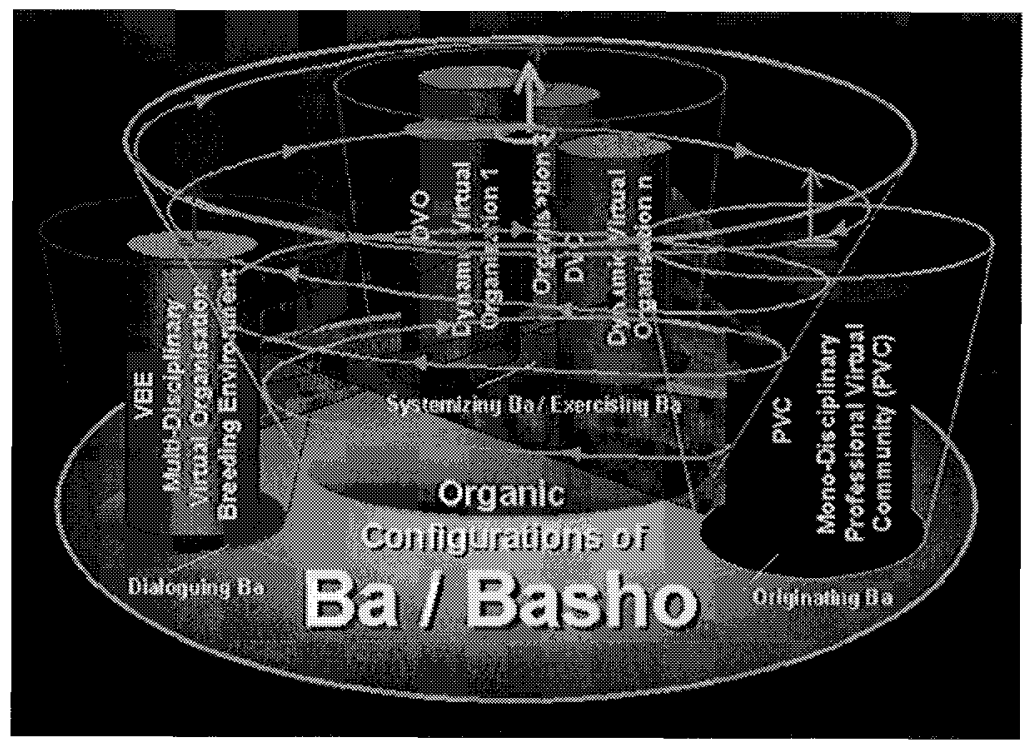

Figure 1 - Environments for learning and knowledge creation, illustrated in an ad-hoc CNO Model (ECOLEAD, ed., 2004)

Legend: = Information as flow

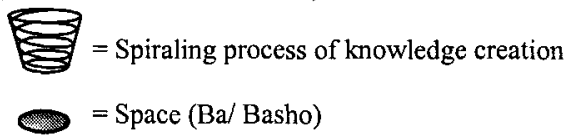

We assume that in the PVCs interactions take place in a process called 'socialisation' (conversion from tacit into tacit knowledge). The ideal type of environment is an Originating $\mathrm{Ba}$, or physical place, where individuals can share feelings, emotions, experiences, and mental models. Conferences, colloquia, and workshops might provide such a space. In a VBE we assume interactions will result in 'externalisation' (the conversion from tacit into explicit knowledge). The ideal environment for this is a Dialoguing $\mathrm{Ba}$ or consciously constructed physical space where mental models (tacit knowledge) are shared, and analyzed. In the DVOs we assume interaction of people will trigger processes of 'combination' and 'internalisation' (conversions from explicit into explicit, and explicit into tacit knowledge). The accompanying ideal types of environments are Systematising and Exercising $\mathrm{Ba}$, partly virtual spaces in collaborative networks, and partly physical spaces, where knowledge is integrated and competencies are trained.

Also at the level of PVC, VBE, and DVO, within the three individual CNO pillars, learning and knowledge creation might take place, see the cones in Figure 1. Individual learning is taking place by self-organising, communicative interaction of the people who participate within the three individual, by ECOLEAD (2004) defined, CNO pillars (PVC, VBE, and DVO); organisational learning seems to be happening in the DVOs only; interorganisational learning is likely to occur at the CNO, seen as a whole or holon. 


\section{CONCLUSIONS AND DISCUSSION}

\subsection{An alternative view of learning in CNOs}

In this paper we have suggested Nonaka's interaction fields as ideal-types of environments for learning in CNOs. But we have to take into account that the basic idea of $\mathrm{Ba}$ or Basho stems from a complete different world context, as was shown in Box 1. However, a closer inspection of that Box learns that the Eastern mindset shows striking similarities with a $C \& C$ approach. For instance, the holistic, non-dualistic method, the correlative thinking, and the flexible view of time and space are also characteristics of CST. Therefore, we think Nonaka's concepts - especially the distinction between physical versus virtual Basho - might be helpful for a better holonic understanding of the complex interplay between individual, organisational and inter-organisational learning in $\mathrm{CNOs}$, and might be regarded as an early, orientallybased view of CST.

\subsection{Learning versus knowledge creation: Different viewpoints of the same com- municative interactions}

As we have seen in the previous paragraphs, Nonaka's theory focuses on knowledge creation (c.f., Nonaka, 1991; Nonaka \& Takeuchi, 1995). In CST, learning is put more central (c.f., Van Eijnatten \& Putnik, 2004). We think that learning and knowledge creation can be viewed as indications of one and the same communicative interaction process, seen from different angles or perspectives. We second Stacey in defining the process of learning as "the activity of interdependent people, which can only be understood in terms of self-organising communicative interaction and power relating in which identities are potentially transformed" (Stacey, 2003: p. 325). This process of self-organising communicative interaction and power relating might result in both knowledge creation and knowledge destruction as a $\mathrm{CNO}$ goes through the different stages of its life cycle.

\subsection{The possibility of 'real novelty'}

Stacey et al. (2000) claim that conventional Systems Thinking basically is unable to create novelty, because - in line with Formative Teleology - the system's ultimate goal already is known in advance (c.f., Table 1). Although we concur with Stacey and associates that previous system approaches indeed suffered from a Kantian split, we think that the term 'system' as such is not fully obsolete yet, as long as it is seen as a whole-part or holon. Therefore, a methodological migration was suggested from Open Systems Thinking into Chaordic Systems Thinking (Van Eijnatten, 2000; Van Eijnatten \& Hoogerwerf, 2000). We claim that CST will prevent any split between different frameworks of causality. By the identification of the five chaordic properties - conciousness, connectivity, indeterminacy, dissipation, and emergence - we propagate in line with Stacey et al. (2000) the use of a Transformative Teleology. In that sense we speak of organisational renewal or organisational novelty as transformation instead of reformation, the latter we have called improvement, see Table 1 .

Although Nonaka and Konna (1998: p. 41) also are talking about "transcending one's own limited perspective or boundary", which might be interpreted as a process 
leading to novelty, Nishida (1970: p. 80-84) seems to seriously question whether novelty can be 'created' (Tanaka, undated), or that it is just a matter of "pure experiencing the unfolding of a complex reality". Although both path and goal might be unknown in advance, learning takes place by immediate perception or intuition. This issue might be interesting enough to deal with in more detail, in another paper.

Table 1 - Real novelty as contrasted with improvement and renewal

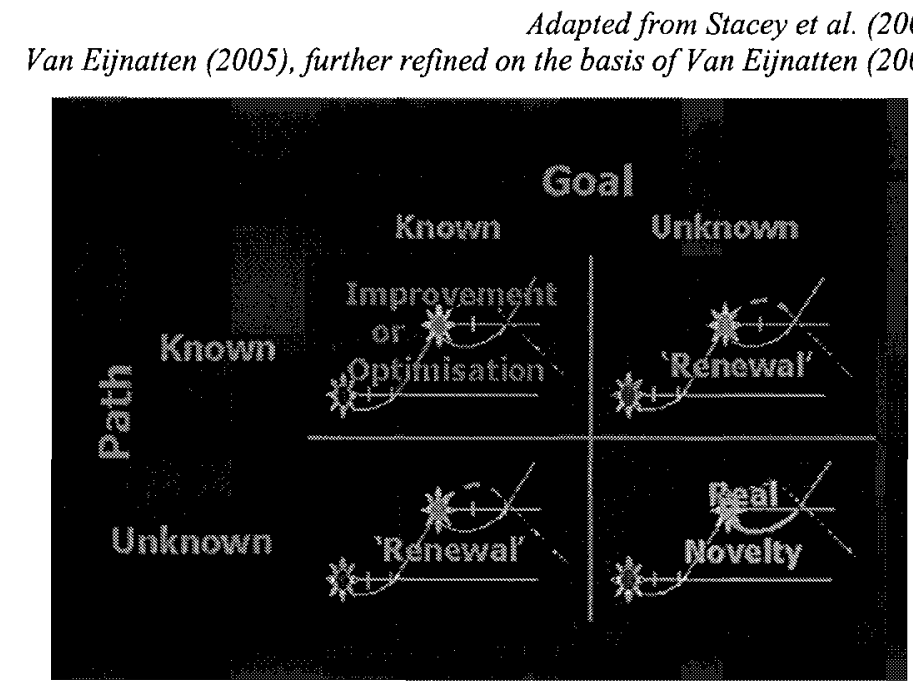

\section{REFERENCES}

1. Camarinha-Matos, L. M.; Afsarmanesh, H.; Ollus, M. - ECOLEAD: A holistic approach to creation and management of dynamic virtual organizations, in Collaborative Networks and their Breeding Environments, Springer, Sept 2005.

2. Chia, Robert. Complex Thinking in 'Eastern Thought': Non-Presence, Decenteredness and the Unspeakable. Paper presented at the CSTT/ ESRC workshop 'Language and Complexity', Centre for Culture, Social Theory \& Technology, Keele University, Keele, Staffordshire, UK, 1998.

3. Chia, Robert. From Knowledge-Creation to the Perfecting of Action: Tao, Basho and Pure Experience as the Ultimate Ground of Performance. School of Business and Economics, Exeter University, Exeter, Devon, UK, Paper 02/ 04, 2002.

4. Cunha, MM, Putnik GD. "Market of Resources as an Environment and Enabler for Agile/ Virtual Enterprise Dynamic Integration and Business Alignment". In: Encyclopedia of Information Science and Technology. Hershey, PA: Idea Group Publishing, forthcoming in 2005.

5. ECOLEAD, ed. Creating Necessary Foundations and Mechanisms for Establishing an Advanced Collaborative and Network-Based Industry Society in Europe. ECOLEAD: European Collaborative Networked Organisations Leadership Initiative. Brussels, Information Society Technology Programme, Sixth Framework Program, Integrated Project IP 506958, 2004.

6. Eijnatten, Frans M. van. From Intensive to Sustainable Work Systems: The Quest for a New Paradigm of Work. Keynote Speech at the TUTB/ SALTSA Conference "Working Without Limits: Re-Organising Work and Reconsidering Workers' Health". Brussels: 25 September 2000.

7. Eijnatten, FM van. "Chaordic Systems Thinking: Chaos and Complexity to Explain Human Performance Management". In: Business Excellence 1: Performance Measures, Benchmarking and Best Practices in New Economy, G.P. Putnik, A. Gunasekaran, eds. Braga/ Guimarães, Portugal, School of Engineering: University of Minho Press, 2003: 3-18.

8. Eijnatten, Frans M. van. A Chaordic View of Collaborative Networked Organisations. Yokohama, Japan: Yokohama National University. Unpublished paper, 2005. 
9. Eijnatten, FM van, Hoogerwerf, EC. "Searching for New Grounds: Beyond Open Systems Thinking". In: The New Sociotech: Graphity on the Long Wall, E. Coakes, R. Lloyd-Jones, D. Willis, eds. London: Springer-Verlag, 2000: 39-50

10. Eijnatten FM van, Putnik GD. Chaos, complexity, learning, and the learning organisation: Towards a chaordic enterprise. The Learning Organisation 2004; 11 (6): 418-429.

11. Miles RE, Snow CC. Fit, Failure and the Hall of Fame. California Management Review 1984; 26 (3) Spring: 10-28.

12. Miles RE, Snow CC. Organisations: New Concepts for New Forms. California Management Review 1986; 28 (3) Spring: $62-73$.

13. Miles RE, Snow CC. Fit, Failure and the Hall of Fame. How Companies Succeed or Fail. New York, NY: The Free Press, 1994.

14. Nishida, Kitarō. An Inquiry into the Good (Zen No Kenkyuu: 1921). New Haven, CT: Yale University Press. English translation by Masao Abe, and Christopher Ives in 1990; earlier edition in 1960: A Study of Good. Tokyo, Japan: Japanese Government Printing Office, translated by Valdo $\mathrm{H}$. Viglielmo; also published in 1988, Westport, CT: Greenwood Press.

15. Nishida, Kitarō. Fundamental Problems of Philosophy (Tetsugaku No Kompon Mondai: 1933/34): Volume I, The World of Action; and Volume II, The Dialectical World. Tokyo, Japan: Sophia University, English translation by David A. Dilworth in 1970

16. Nonaka, I. A Dynamic Theory of Organisational Knowledge Creation. Organisation Science 1994; 5 (1), 14-37.

17. Nonaka I, Konno N. The Concept of 'Ba': Building a Foundation for Knowledge Creation. California Management Review 1998; 40 (3) Spring: 1-15.

18. Nonaka, Ikujiro, Nishiguchi, Toshihiro. Introduction: Knowledge Emergence. In: Knowledge Emergence: Social, Technical, and Evolutionary Dimensions of Knowledge Creation, I. Nonaka, T. Nishiguchi, eds. New York, NY: Oxford University Press, 2001: 3-9.

19. Nonaka, Ikujiro, Takeuchi, Hirotaka. The Knowledge- Creating Company: How Japanese Companies Create the Dynamics of Innovation. New York, NY: Oxford University Press, 1995.

20. Nonaka I, Toyama R. The Knowledge-Creating Theory Revisited: Knowledge Creation as a Synthesising Process. Knowledge Management Research and Practice 2003; 1 (1): 2-10.

21. Nonaka I, Toyama R, Konno N. SECI, Ba and Leadership: Unified Model of Dynamic Knowledge Creation. Long Range Planning 2000a; 33 (1): 5-34.

22. Nonaka I, Toyama R, Nagata A. A Firm as a Knowledge-Creating Entity: A New Perspective on the Theory of the Firm. Industrial and Corporate Change 2000b; 9 (1): 1-20.

23. Nonaka, Ikujiro, Konno, Noboru, Toyama, Ryoko. Emergence of 'Ba'. In: Knowledge Emergence: Social, Technical, and Evolutionary Dimensions of Knowledge Creation, I. Nonaka, T. Nishi-guchi, eds. New York, NY: Oxford University Press, 2001: 13-29.

24. Polanyi, Michael. The Tacit Dimension. New York, NY: Anchor Books, 1967.

25. Putnik GD, Cunha MM, Sousa R, Ávila P. Virtual Enterprise Integration: Challenges of a New Paradigm. In: Virtual Enterprise Integration: Technological and Organisational Perspectives. G.D. Putnik, M.M. Cunha, M.M., eds. Hershey, PA: Idea Group Publishing, forthcoming in 2005.

26. Shimizu, Hiroshi. Ba- Principle: New Logic for the Real- Time Emergence of Information. Holonics 1995; 5 (1): 67-79.

27. Stacey RD. Learning as an Activity of Interdependent People. The Learning Organisation 2003; 10 (6): $325-331$.

28. Stacey, Ralph, Griffin, Douglas, Shaw, Patricia. Complexity and Management: Fad or Radical Challenge to Systems Thinking? London: Routledge, 2000.

29. Tanaka, Yutaka. The Topos of Nothingness and the World Process: An Essay on Process Cosmology in Science and Religion. Tokyo, Japan: Sophia University, Department of Philosophy, undated.

30. Yuasa, Yasuhito. The Body: Toward an Eastern Mind-Body Theory. Albany, NY: State University of New York (SUNY) Press, translation by S. Nagatomo, \& T.P. Kasulis, 1987.

${ }^{i}$ The University of Minho is the partner of the EU FP6 Network of Excellence I*PROMS - Innovative Production Machines and Systems. 